\title{
A Study on English as a Lingua Franca: Japanese University Students' Barriers to Communication
}

\section{Sawako Kato}

\author{
Ed. D., Bunkyo Gakuin University, Tokyo, Japan
}

Sandra Tanahashi

Bunkyo Gakuin University, Tokyo, Japan

Doi:10.5901/jesr.2013.v3n7p300

\begin{abstract}
In this global society, almost all of us agree that English acts as a lingua franca. However, non-native speakers often make L1 influenced mistakes including structural or grammatical errors, or mistakes in vocabulary usage. These mistakes can interfere in communication with native speakers. In this study, a sample of 101 Japanese university students who had studied English for six years before entering university (i.e. nonnative speakers) participated in translating certain sentences into written English. Then the degree to which native speakers understood these translations was examined. Native speakers marked the data as one of three types: natural, not natural but comprehensible, or incomprehensible. Next, data that was marked as either comprehensible or incomprehensible was examined to identify the type of errors that occurred most frequently. The types of errors in students' translations of sentences were divided into three categories: (1) errors influenced by L1, (2) errors stemming from a lack of grammatical knowledge, and (3) errors which arose from a poor understanding of vocabulary. Finally, the data completed by our sample was used to find the kinds of elements that become obstacles to communication and the most difficult ideas for the students to express.
\end{abstract}

\section{Introduction}

In Japan English is taught as a Foreign Language, not a second language, as English learners have few chances to use it in authentic situations. This means that students learn their English in the classroom under conditions contrived by the instructor and/or the textbook that will give students practice with vocabulary and common grammatical patterns.

When students are evaluated on their understanding of English, their success or failure is measured based on their rote memorization and ability to perform well on written exams. Instructors are usually looking for just one correct answer when there are often many possible answers if the student knows English well.

English education in Japan has a long tradition of seeking "native" fluency. Students with anything less are reluctant to use their English. Even after entering university they spend much too long formulating a sentence before writing or speaking English. Moreover, their English ability is evaluated based on Standard English (SE). However, following the movement to accept English as a lingua franca, Japanese English teachers are beginning to recognize that we should accept varieties of English. As English is accepted as an international language with many non-native speakers, we need to adopt new criteria for evaluating students' English ability from the perspective of communication instead of grammar.

In this study we discuss Japanese university students' communicative ability referring to English as a lingua franca. We focus on the semantic and pragmatic content of communication rather than on external form and accuracy based on SE. By exploring the factors that may interfere in communication with native speakers, we feel we can make suggestions that will benefit both students and teachers of a Second Language ( ESL) when using English as a lingua franca.

Our research has two phases. First we explored the typical errors-including structural or grammatical errors, or mistakes in vocabulary usage-in written translations. Second, native speakers evaluated translations in terms of comprehensibility. We used written translation for our research because it is less influenced by internal or external learning factors, and has a smaller set of variables than spoken translation. 


\section{Review of the Literature}

\subsection{Research on English as a lingua franca}

When we discuss "English as a lingua franca", we must define what this means. According to Jenkins (2010) "a lingua franca is a contact language used among people who do not share a first language, and is commonly understood to mean a second or subsequent language of its speakers" (p.1). The original definition of a lingua franca was a language that had no native speakers (NSs). However, English has gradually become accepted as a lingua franca because of the increase in the number of English speakers in the world, the vast majority of which are non-native speakers who use English to communicate with each other rather than with native speakers

\subsection{Research on Error Analysis}

Error Analysis flourished in the 1970s and 1980s as one of the first ways to investigate English as ESL acquisition. Major research on ESL error analysis undertaken until the early 1990s focused on the influence of native language (NL) on ESL and most of them are compared students' English to native-like accuracy and fluency. In a 1974 study, Selinker reported five sources of errors: 1. Language transfer, 2.Transfer of training, 3. Strategies of second language learning, 4. Strategies of second language communication, and 5.Overgeneralization of target language linguistic material (p.9). James (1998) showed three main diagnosis-based categories of error: "1. Interlingual 2. Intralingural and 3. Induced errors" (p.178).

In Japan, the research on EFL error analysis gradually appeared. Tagashira \& Yamada (2004) reviewed the previous cross-sectional studies for Japanese learners and pointed out the problems influenced by L1. However, recently error analysis has regained popularity for more specific uses. It is because "error analysis gives language teachers and learners the strategies to overcome or minimize their disabilities and the disabling effect of their ignorance" (Miyake: 1997:31). Miyake (1997) classified errors into five categories: 1.Interlingual interference, 2.Intralingual interference, 3.L2 learning strategies, 4.Communication strategies, and 5.Errors due to the effects of teaching. Matsuoka (2006) concluded his research by stating, "beginning level students make more word-for-word translation errors that are caused by the lack of the correct lexical knowledge of English" (p.107).

\section{Purpose of this Study}

The purpose of this study is to discuss how Japanese English teachers should teach English as a lingua franca.

1. Can native teachers understand written translations by Japanese students?

2. What kind of errors (such as structural or grammatical errors, or mistakes in vocabulary usage) are often observed in written translations by Japanese university students?

3. What errors in translations become obstacles to communication with native speakers?

\section{Methodology}

\subsection{Samples}

This study was completed in two parts. The first part was a sample of 101 Japanese university students from the Health Science Technology and Human Studies departments in Bunkyo Gakuin University in Tokyo, Japan. All of the students had studied English for six years prior to entering the university. These students were asked to translate four tasks from Japanese into English. The students' translations were divided into categories based on the types of errors made. Five native English speakers who teach English in Tokyo analyzed the students' translation errors.

Part two of this study was further analyzing of the translation errors by 13 native English speakers in Australia who teach English at Swinburne College in Melbourne.

\subsection{Survey instruments}

The questionnaire for our samples contained four sentences (listed below as Tasks 1-4) in Japanese that needed to be translation. They were allowed to use dictionaries. These sentences included words and phrases that Japanese students 
tend to have trouble with as outlined in studies by Selinker (1972) and Matsuoka (2006). The sentences were taken from an English writing book by Ishi and Kito (2007).

Task 1: Sutoresu ga tamaru to okoripoku naru mono desu.

Task 2: Orinpiku no hata no itsutsu no wa wa itsutsu no tairiku wo sashiteimasu.

Task 3: Kono seihin wa karukute joubu da toiu riten ga arimasu.

Task 4: Nihongo niwa hayakuchikotoba ya kaibun nado omoshiroi kotoba asobi ga houfu ni aru.

\subsection{Data Collection Procedure}

First the 101 students translated the four written Japanese sentences into English and the data was collected from June 18 to June 26,2009 by the researchers.

Second the students' compositions were evaluated by five native speakers and divided into one of three groups:

Group 1-Natural/grammatically correct

Group 2-Comprehensible/ some grammatical mistakes, or

Group 3-Incomprehensible/grammatically incorrect

Next, the researchers conducted an error analysis. The data in Groups 2 and 3 was categorized into the type of error that occurred: 1. Grammar/Word order (native L1Transfer), 2. Syntax/Grammar (L1Transfer), and 3. Lexis (i.e. The students translate word-for-word because they regard translation as a mechanical process).

Finally, based on the first step results, 84 students' compositions were selected as examples of typical errors. These were evaluated again by 13 native speakers in Australia. The native speakers who participated in this study were selected solely based on the convenience of the researchers.

\section{Results}

To answer research question 1-Can native teachers understand written translations by Japanese students? -the students compositions were evaluated by native English teachers from Japan. The five native speakers divided the translations into one of three groups: Group 1-Natural/grammatically correct, Group 2-Comprehensible/ some grammatical mistakes, or Group 3-Incomprehensible/ grammatically incorrect. The results by Task were as follows.

Task 1. The expected English was, "He becomes irritable when he is stressed."

According to the evaluation of the 5 native teachers, $16 \%$ of the students wrote natural English, $6 \%$ wrote comprehensible English, and 70\% wrote incomprehensible English (8\% wrote nothing).

\begin{tabular}{ll}
\multicolumn{2}{c}{ Example of the students' translations: } \\
\hline comprehensible & incomprehensible \\
\hline When stress builds up, we become angry. & We are quickly stressful. \\
We get angry easily when stress builds up. & We like angry when stress built up. \\
\hline
\end{tabular}

Task 2. The expected sentence was, "The five rings on the Olympic flag represent the five continents."

According to the evaluation of the 5 native teachers, only $1 \%$ could write the correct sentence, $14 \%$ were comprehensible, and $74 \%$ were incomprehensible ( $11 \%$ no answer).

Example of the students' translations:

\begin{tabular}{ll}
\hline comprehensible & incomprehensible \\
\hline Five rings in the flag of Olympic means five continents. & $\begin{array}{l}\text { Olympic flag's five rings are mean five continent. } \\
\text { Five rings of Olympic frag designate five continents. }\end{array}$ \\
\hline
\end{tabular}

Task 3. The expected sentence was, "This product has the advantage of being light and durable."

According to the evaluation of 5 native teachers, $9 \%$ of this sample could write the natural sentences, $23 \%$ comprehensible, and 60\% incomprehensible (8\%, no answer). 
Examples of the students' translations:

\begin{tabular}{ll}
\hline comprehensible & incomprehensible \\
\hline This product has an advantage of light and strong. & This product is light and strong about an advantage. \\
The product has strong point that is light and strong. & This product have advantage light and strong. \\
\hline
\end{tabular}

Task 4. The expected sentence was: "In Japanese there is a lot of interesting word play such as tongue twisters and palindromes."

According to the evaluation of the 5 native teachers, $0 \%$ of the sample could write a natural sentence, $16 \%$ were comprehensible, and $73 \%$ were incomprehensible ( $11 \%$ no answer).

Example of the students' compositions:

\begin{tabular}{ll}
\hline comprehensible & incomprehensible \\
\hline Japanese is a lot of word game, which are tongue & Japanese have abundant language play that tongue \\
twister and palindrome. & twister and palindrome. \\
Japanese is a lot of fun word game. & $\begin{array}{l}\text { In Japanese, tongue twister and palindrome is } \\
\text { interesting word play is many. }\end{array}$ \\
\hline
\end{tabular}

To answer the research question 2-What kind of errors are often observed in written translations by Japanese university students? - the error analysis was conducted. The results are as follows:

Errors in Task 1. The main errors were using incorrect subjects influenced by Japanese. The subject is often omitted in Japanese and so it is easy for students to mistake the topic maker, "wa", for the subject. Of the sample, 18\% used we/you/he/she as the subject, $50 \%$ used stress, $30 \%$ used it, and $2 \%$ used other words as the subject. Another error was using the wrong verb such as build (up) (20 cases), pile (up) (7 cases), gather ( 6 cases), collect (2 cases), accumulate (1 case), get (3 cases), and no verb, etc. (21 cases).

Errors in Task 2. The main errors in this task were made by using the wrong verb and/or translating Japanese particles incorrectly. Examples of the wrong verb they used included point (at/for/to) (34 cases) /mean (17 cases) /show ( 9 cases )/is ( 9 cases) /pierce ( 2 cases) /suggest \& refer ( 2 cases) /and others (no verb, etc.) (10 cases). Particles were translated as of (81cases) / on (2cases) Olympic's (8 cases) flag's (4 cases). Those are Lexis errors ( i.e. the students translate word-for-word because they regard translation as a mechanical process).

Errors in Task 3. The main errors were lexis errors influenced by Japanese. In place of articles, the sample used the wrong words such as product (31 cases), goods ( 5 cases), article (14 cases), manufacture ( 3 cases), this ( 7 cases), and others. They also used the wrong adjectives including strong (42 cases), tough (4 cases), well (2 cases), and others (12). Structure pattern errors included there is (7 cases), have (or has) advantage/good/strong point/merit (21 cases), product is advantage (6 cases).

Errors in Task 4. They made structure pattern errors. In particular, the students used Japanese word order (S/O/V) instead of using English word order (S/V/O). They started the sentence with: Japanese is (11 cases), Japanese has (have) (46 cases), In Japanese ...there is (are) (3cases), and no answers (9 cases). They also used the wrong adjective such as a lot of (8 cases), a lot (10 cases), lots of (1 case), abundant(ly) (7 cases), many (17 cases), rich(ly) (6cases).

Results of research question 3-To find what errors in translations become obstacles to communication with native speakers, 20-23 examples of the sample's translations for Tasks 1-4 that were categorized as either comprehensible or incomprehensible (not examples of natural translations) by the 5 native speakers in Tokyo, were analyzed again by 13 native English teachers in Australia.

As the results show native teachers found many of the sentences with grammatical errors comprehensible. Errors related to plural forms, the omission of "the", or using inappropriate verbs or adjectives did not hinder understanding.

Examples: When stress builds up, I become anger.

Five circle of Olympic flag means five continent.

This product has an advantage of light and strong.

The product has (a) strong point that is light and strong.

This goods have some merits that is light and strong.

There are many interesting language game, such as tongue

twister, palindrome in Japan.

However, errors such as wrong verb use and wrong word order did hinder comprehension. Examples: 
Task 1: Incomprehensible translations were:

1.We like angry when stress built up. 2.We get mad, when spend stress.

3.What we become irritable, when stressed. 4.We are quickly stressful.

Numbers 1 and 2 have fatal mistakes. They use the wrong verbs. Number 3 is meaningless because it is logical from a common-sense view. Number 4 is grammatically (structurally) incorrect.

Task 2: Incomprehensible translations were:

1. Flag of the Olympic five rings aims. Five continent is.

2. Five rings of Olympics' frag point to five.

3. Olympic is in five ring. It's fie land.

Number 1 uses the wrong verb followed by an incomplete sentence. Numbers 2 and 3 have spelling errors and fatal word choices.

Task 3:Incomprehensible translations were:

1. This goods have advantage which flat and durable.

2. This product is advantage. It's light strong.

3. This product has the advantage. That's a light and strong.

Number 1 has the wrong word choice and the wrong order so that the wrong word is modified. Numbers 2 and 3 were word-for-word translations influenced by L1.

Task 4:Incomprehensible translations were:

1. The Japanese have abundantly interesting a ply language lie a tongue twister and a palindrome.

2. Japanese has many word games that like jawbreakers and a palindrome.

3. It has Japanese abundantly interesting play on word. A tongue twister and a palindrome.

Number 1 has fatal spelling mistakes. Numbers 2 and 3 are grammatically wrong and have the wrong word order and structure.

\section{Discussions and Conclusions}

\subsection{Japanese university students' typical errors}

The results of this study show that the majority of Japanese college students find it difficult to impossible to convey their ideas in English. It is lamentable to find out that only $8.5 \%$ of the students in this sample could write correct translations in natural English. This result confirms that Japanese students lack communicative English ability. Their errors were mainly caused by a negative influence from their NL, which occurs when a NL system is different from Target Language (TL) norms. The learner incorrectly brings a NL behavior in processing TL features (Matsuoka; 2006).

The clearest evidence of characteristic negative NL transfers was found in this study in the form of wrong word order. As we see in Task 1, 80\% of the students used "stress" or "it" as the subject of the sentence. This is because in Japanese an initial word followed by the topic markers such as "ga" "wa" or "de wa", is the subject in many cases. What is more confusing for Japanese students is that the subject is often omitted from an English sentence. As a result, this typical error is made. One example of this mistaken word order would be, "kinou (wa) baito datta" which means "I worked part-time job yesterday" (or literally, yesterday part-time job worked). Many students translate this as: Yesterday was part-time job.

Another characteristic negative NL transfer is word-for-word translation leading to wrong word use. As we have seen in the results of Task 1 and 2, if a student translates word-for-word, the sentence ends up being awkward.

\section{Examples for Task 1}

correct translation: $\quad$ (he) is stressed /(he) feels stress

incorrect translation: $\quad$ stress accumulates, stress piles up, etc.

\section{Examples for Task 4}

\section{correct translation: $\quad$ five rings represent}

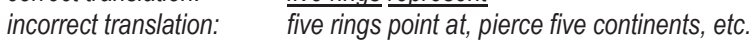

These poor translations occur when sentences are translated word-for-word without thinking about the context of the sentence and common usage in the TL. Their translations were similar to those done by online electronic translators. 
They use the same verbs as the translators as if the students have a similar formula as the translator. Students should realize that every sentence is unique. Language is fluid and not mechanically structured, so every sentence must be translated not mechanically but in a unique manner to fit the situation. Language does not conform to a predetermined formula.

Based on the evaluations by the native speakers we can see that learning word order/structure is more important than learning grammar. English education in Japan has a long tradition of putting an importance on grammar, but there are numerous expressions which cannot be explained grammatically but are regarded as natural. Grammar focused teaching is not the best ways to teach English.

We found from the results of the error analysis that the five native speakers who are accustomed to what might be called "Japanese-English", agreed that the sentences with errors in prepositions, plural forms, and the third person singular are comprehensible for them. In other words, the omission of articles and errors with plural forms do not usually lead to the sentences becoming incomprehensible. This shows that some grammatical points, though seen as necessary for correct Standard English, are not a critical factor for communication.

Instead it is incorrect word order that often leads to incomprehensible translations for native speakers. If a sentence has the correct word order, there is a much better chance that it will be understood.

\subsection{How should we English teachers in Japan encourage the use of English as a lingua franca?}

In our study we found that native speakers could understand Japanese students' translations when they made careless errors with grammar or used words with slightly different meanings. Errors related to plural forms, the omission of "the", or using inappropriate verbs or adjectives were in many cases comprehensible.

On the other hand, native speakers could not understand when students' made structural mistakes, or when the sentences use wrong verbs or wrong subjects.

It seems that a better grasp of word order and vocabulary will help students to communicate more effectively than an emphasis on grammar. In the end, it is the meaning of the message we are trying to convey that holds importance, not whether the message follows the norms of SE.

\section{References}

Ishi, T. \& Kito, T. (2007). Step up to Better English. Asahi Press.

James, C. (1998). Errors in Language Learning and Use: Exploring Error Analysis. London: Longman.

Jenkins, J. (2010). English as a Lingua Franca; Attitude and Identify. Oxford.

Matsuoka, S. (2006). The role of native language in Japanese EFL/ESL learner's recurring errors: a literature review of language transfer. The Journal of Ryukoku University. 15, pp. 93-109.

Mishimaki, N. (2006). English Order. Tokyo: Asa Publishing Company.

Miyake, M.(1997), Error Analysis: Its Historical Progression and its Characteristics,

Kawasaki Journal of Medical Welfare, 3(1), pp. 31-36.

Seidlhofer, B. "Common Property: English as a Lingua Franca in Europe." International Handbook of English Language Teaching, ed. by Jim Cummins and Chris Davison. Springer, 2007.

Selinker, L. (1974). Interlanguage. In Richards, J. (Ed.). Error analysis: Perspectives on Second Language Acquisition. 31-54. Essex: Longman.

Shibata, Akiko(2004), Teaching English as an International Language in Japan, Journal of Hokkaido College, No.37 pp.75-93

Tagashira, K. \& Yamato, T. (2004). Pragmatic Development of Japanese EFL Learners:

What we can see from the Cross-sectional Studies, Institute for Foreign Language Education Center, Hiroshima University, no 9, pp. 155-164.

Yoshida, K. \& Yanase, K. (2003). A suggestion for teaching English making use of Japanese. Tokyo: Taishukan. 